\title{
Supplement to A novel method for cold region streamflow hydrograph separation using GRACE satellite observations
}

\author{
Shusen Wang ${ }^{1}$, Junhua $\mathrm{Li}^{1}$, and Hazen A. J. Russell ${ }^{2}$ \\ ${ }^{1}$ Canada Centre for Remote Sensing, Natural Resources Canada, Ottawa, K1A 0E4, Canada \\ ${ }^{2}$ Geological Survey of Canada, Natural Resources Canada, Ottawa, K1A 0E8, Canada \\ Correspondence to: Shusen Wang (Shusen.Wang@Canada.ca)
}

\section{S1 Introduction}

This Supplementary Materials contains two sections. The first Section (S2) gives a brief description for the six methods of hydrograph separation provided with the U.S. Geological Survey Groundwater Toolbox. They include PART, HYSEP (Fixed Interval, Sliding Interval, and Local Minimum), and BFI (Standard and Modified). More details can be found in Barlow et al. (2015) and Sloto and Crouse (1996). The second Section (S3) gives the detailed information for the data used in this study. They include air temperature, snow water equivalent, streamflow, and total water storage change.

\section{S2 Summary of the hydrograph separation methods provided with the U.S. Geological Survey}

\section{Groundwater Toolbox.}

\section{S2.1 HYSEP}

The HYSEP program uses three methods to separate the baseflow and surface runoff components of a streamflow hydrograph. They are the fixed interval, sliding interval, and local minimum. These methods can be described conceptually as three different algorithms to systematically draw connecting lines between the low points of the streamflow hydrograph. The sequence of these connecting lines defines the base-flow hydrograph. The techniques were originally developed by Pettyjohn and Henning (1979). The duration of surface runoff is calculated from the empirical relation:

$$
\mathrm{N}=\mathrm{A}^{0.2}
$$

where $\mathrm{N}$ is the number of days after which surface runoff ceases, and $\mathrm{A}$ is the drainage area in square miles (Linsley et al., 1982). The interval $2 \mathrm{~N}$ used for hydrograph separations is the odd integer between 3 and 11 nearest to $2 \mathrm{~N}$. In this study, the interval of 11 days is used for hydrograph separations.

\section{(1) Fixed-Interval Method}

The fixed-interval method assigns the lowest discharge in each interval $(2 \mathrm{~N})$ to all days in that interval starting with the first day of the period of record. The method can be visualized as moving a bar $2 \mathrm{~N}$ days wide upward until the bar first intersects the hydrograph. The discharge at that point is assigned to all days in the interval. The bar is then moved $2 \mathrm{~N}$ days horizontally, and the process is repeated. The assigned values are then connected to define the baseflow hydrograph. 


\section{(2) Sliding-Interval Method}

The sliding-interval method finds the lowest discharge in one half the interval minus 1 day [0.5(2N-1) days] before and after the day being considered and assigns it to that day. The method can be visualized as moving a bar $2 \mathrm{~N}$ wide upward until it intersects the hydrograph. The discharge at that point is assigned to the median day in the interval. The bar then slides over to the next day, and the process is repeated. The assigned daily values are then connected to define the baseflow hydrograph.

(3) Local-Minimum Method

The local-minimum method checks each day to determine if it is the lowest discharge in one half the interval minus 1 day [0.5 $(2 \mathrm{~N}-1)$ days] before and after the day being considered. If it is, then it is a local minimum and is connected by straight lines to adjacent local minimums. The baseflow values for each day between local minimums are estimated by linear interpolations. The method can be visualized as connecting the lowest points on the hydrograph with straight lines.

\section{S2.2 BFI}

The BFI program (Wahl and Wahl, 1995) is based on a set of procedures developed by the Institute of Hydrology (1980a, b) of United Kingdom in which the streamflow record is partitioned into intervals of length $\mathrm{N}$ days. The minimum streamflow during each $\mathrm{N}$-day interval then is identified and compared to adjacent minimums to determine "turning points." If 90 percent of a given minimum (the "turning point test factor") is less than both adjacent minimums, then that minimum is a turning point. The base-flow hydrograph is completed by connecting the turning points. In the BFI-modified approach, parameter $\mathrm{f}$ is replaced by a daily recession index $\mathrm{K}^{\prime}$, and the turning-point test considers the exact number of days between turning-point candidates. Results obtained by the modified approach will usually be very similar to those obtained by the standard approach if

$$
\mathrm{K}^{\prime}=\mathrm{f}(1 / \mathrm{N})
$$

For values of $\mathrm{N}=5$ days and $\mathrm{f}=0.9$, the equivalent value of $\mathrm{K}^{\prime}$ is 0.979 . One modification was made to the BFI program for implementation in the GW Toolbox. In the original program, turning points were identified for each individual year, with partitioning restarted on day 1 of each year, and artificial (or virtual) turning points were created at the yearend boundaries. In the GW Toolbox implementation, turning points are identified continuously throughout the entire period of record, which avoids the creation of artificial turning points at the end of each year. This modification also changes how the daily values are partitioned after a year is completed in which the number of days in the year is not an even multiple of $\mathrm{N}$. In this study, the partition length is 5 days, turning point test factor $(\mathrm{f})$ is 0.9 , and daily recession index ( $\left.\mathrm{K}^{\prime}\right)$ is 0.97915 . The parameters follow the relationship of Equation (A2).

\section{S2.3 PART}

The PART program (Rutledge, 1998) equates base flow to streamflow on days that are designated as being unaffected by surface runoff or interflow (stormflow), and linearly interpolates between these days to determine baseflow for the remainder of the hydrograph. Days that are unaffected by surface runoff are identified by the program as those preceded by $\mathrm{N}$ days of continuous recession. 


\section{S3 Data description}

\section{S3.1 Air temperature (T)}

The daily $\mathrm{T}$ in this study for Albany River watershed was calculated from the Global Land Data Assimilation System (GLDAS) meteorological forcing (http://mirador.gsfc.nasa.gov/). The GLDAS data were acquired as part of the mission of NASA's Earth Science Division and archived and distributed by the Goddard Earth Sciences Data and Information Services Center. The data is provided at a 3-hour time step and a spatial resolution of 0.25 by 0.25 degree latitude/longitude. The daily $\mathrm{T}$ of a grid is taken as the average of the eight readings of the day, and the watershed $\mathrm{T}$ is the average of the $\mathrm{T}$ values of all the GLDAS grids within the watershed. There are four weather stations located in the Albany River watershed with air temperature measurement available during the study period. A comparison of the station measurements and the GLDAS temperatures in the corresponding grids show that they are highly consistent, with average biases varying from $-0.85^{\circ} \mathrm{C}$ to $0.01^{\circ} \mathrm{C}$ and linear correlation coefficients varying from 0.96 to $~ 0.99$ (Wang, 2019).

\section{S3.2 Snow water equivalent $\left(S_{n}\right)$}

The daily snow water equivalent in this study for Albany River watershed was obtained from the Ecological Assimilation of Land and Climate Observations model (EALCO) of Natural Resources Canada. The EALCO model is a land surface model developed for simulating terrestrial ecosystem physical, physiological and biogeochemical processes using in situ and remote sensing observations (Wang et al., 2013, 2015). Details related to the dynamic snow simulation in EALCO can be found in Zhang et al. (2008). The EALCO snow water equivalent data product is provided at 5-km spatial resolution and daily temporal resolution. In this study, the watershed snow water equivalent is the average of the snow water equivalent values of all the EALCO grids within the watershed. The monthly snow water equivalent is averaged over the days that are used in the GRACE TWS solutions for that month.

\section{S3.3 Streamflow (Qobs)}

The Albany River has several hydrometric stations managed by Water Survey of Canada (WSC). This study used data from the most downstream gauge station in order to have the maximum drainage area possible (Gauge Station \#04HA001, Albany River near Hat Island, latitude 51.3306, longitude -83.8333). The observed daily streamflow at the hydrometric station was downloaded from the WSC website (http://www.ec.gc.ca/rhc-wsc/). The original streamflow is in $\mathrm{m}^{3} \mathrm{~s}^{-1}$ and it was converted to water depth (mm) using the drainage area. The quality of the streamflow data was cross checked by inter-comparisons with nearby gauge measurements over the region. Specifically, there are two major watersheds adjacent to the Albany River watershed: the Attawapiskat watershed in the northwest (Station \#04FC001) and the Moose watershed in the southeast (Station \#04LG004). Comparisons showed that the streamflow for Albany River was reasonably correlated with those for Attawapiskat and Moose, with a linear correlation coefficient of 0.84 and 0.78 (Wang, 2019), respectively. No suspicious outliners were found in the datasets. The streamflow data was also compared with two gauge measurements within the Albany River watershed 
which represent the two major contributory sub-watersheds, namely the Kenogami River (Station \#04JG001) and the Albany River above Nottik Island (Station \#04GD001). The linear correlation coefficients with these two sub-watersheds were 0.91 and 0.83 (Wang, 2019), respectively. The above watersheds are located in a large flat region with similar synoptic and land surface conditions. The correlations among these gauge measurements demonstrate the consistency and reliability in the streamflow data quality.

\section{S3.4 Total water storage change $\left(S_{\text {tot }}\right)$}

The watershed total water storage change was obtained from the GRACE Release-06 V03 spherical harmonic (SH) solutions (Landerer, 2020). The data was downloaded from the GRACE Tellus website (https://podaac.jpl.nasa.gov/GRACE). The GRACE models contain recoverable gravity change signals up to a maximum SH degree 60 , which approximately represents a spatial resolution of $\sim 330 \mathrm{~km}(108,900$ $\mathrm{km} 2$ ). The land grid scale factor, a set of scaling coefficients intended to restore much of the energy removed by the destriping, gaussian, and degree 60 filters to the land grids, was applied to the datasets (Swenson and Wahr, 2006) to minimize the difference between the model's smoothed and unfiltered monthly water storage variations at any geographic location (Landerer and Swenson, 2012). The datasets include monthly TWS time series from three data processing centers: namely CSR (University of Texas/Center for Space Research), GFZ (GeoForschungsZentrum Potsdam), and JPL (Jet Propulsion Laboratory). The differences of the three TWS datasets over Canada's landmass were found minor for the Albany River watershed (Wang and $\mathrm{Li}, 2016$ ). In this study, the average TWS of the three datasets was used. The baseline of the TWS, which was based on the average from January 2005 through December 2010 in the original data, was re-adjusted to the minimum value found over our study period. 